\title{
HIJOS DEL MAR, HIJOS DE LA TIERRA, HIJOS DE LA PILONA. Y algunas notas sobre la gentrificación del Cabanyal (Valencia)
}

\author{
Sergio Braulio VÉLIZ RODRÍGUEZ \\ I.E.S. Juan Goytisolo, Carboneras, Almería (España) \\ vliz3@yahoo.es
}

\begin{abstract}
CHILDREN OF THE SEA, CHILDREN OF THE EARTH, CHILDREN OF THE PILONA. And some notes on the gentrification of the Cabanyal (Valencia)
\end{abstract}

Resumen: Este artículo trata, en primer lugar, de reflexionar sobre un espacio vivido: el del barrio valenciano del Cabanyal desde los años setenta hasta finales del siglo XX. En segundo lugar, ese espacio vivido se contrasta con el vivido por otra persona un siglo antes: Vicente Blasco Ibáñez, quien dedicó su segunda novela, Flor de Mayo, a los pescadores del Cabanyal en 1895. Ambas vidas se proyectan sobre un presente de degradación y de gentrificación, por lo que aprovechamos para aportar algunas observaciones sobre sobre estos dos fenómenos urbanos. Se proyectan, por último, sobre un futuro que permanece abierto.

Abstract: This article aims to reflect, first, about a lived space: the neighborhood of "El Cabanyal" since the seventies to the late twentieth century. Second, this lived space is contrasted with that lived by a different person a century earlier: Vicente Blasco Ibáñez, who dedicated his second novel to the fishermen of "El Cabanyal" in 1895. Both lives are projected on a present characterized by degradation and "gentrification", so we take the opportunity to make some observations about these two urban phenomena; and they are projected finally on a future that remains open.

Palabras clave: Cabanyal. Gentrificación. Comunidad. Urbanismo neoliberal. Pobreza Cabanyal. Gentrification. Community. Newliberal Urbanism. Poverty 
A M $M^{a}$ José Dasí, que en el Santiago Apóstol nos enseñó al mismo tiempo el lenguaje y el silencio de los dioses.

\section{Introducción}

Cabe la vega derecha del Turia, "la poética, la de las fresas de Benimaclet, las chufas de Alboraya y los jardines siempre exuberantes de flores"1de la Malvarrosa, -regada por aguas desviadas a la cequia de Mestalla merced a un azud levantado entre Manises y Paterna, de la que se bifurca el canal de Rams en un punto exacto bajo la calle de Alboraya, que vierte el agua en las cuatro acequias de Riuet, Gas, Pixavaques y La Cadena-, existe, apenas, habiendo sobrevivido a tres incendios generales y otras tantas inundaciones y epidemias, al bombardeo continuado de buques y pavas italianos durante la Guerra Civil, al arrollador, destartalado y ciego urbanismo del desarrollismo franquista, al olvido de una "Transición" que lo tugurizó, y a un proyecto destructor, neroniano, haussmanniano², que pretendía atravesarlo por la mitad con una avenida de cien metros hasta el mar; existe, todavía, el antiguo barrio marinero de Valencia, el Cabanyal ${ }^{3}$.

La épica de los últimos veinte años se conoce bien: el barrio se ha hecho paradójicamente famoso ("parece que no haya otros en Valencia", se llegó a decir en la prensa). Desde los campos de la historia, la antropología, la geografía, la sociología o el urbanismo han ido apareciendo trabajos que, mientras por un lado rescataban la identidad peculiar del "viejo Cabañal", por el otro denunciaban las políticas urbanísticas neoliberales en boga y clasificaban bien pronto las mutaciones del barrio como partes de un proceso de gentrificación ${ }^{4}$

Sin embargo, para quien esto escribe existe un cierto punto ciego antropológico entre el Cabanyal degradado de los tiempos del PEPRI y el viejo Cabanyal de mar y huerta cuyo coloreamiento o relleno podría servir para matizar -o aportar alguna nota más- a ese concepto de "gentrificación" que ya emplean todos con la soltura de un eslogan. Para esta tarea adoptaremos una triple visión de paralaje: en efecto, nacido en el Cabanyal, el autor de este artículo abandonó el lugar a mediados de los noventa sin dejar de visitarlo todos los años al menos cuatro o cinco veces. Como cualquier investigador social sabe, esto tiene sus ventajas y sus desventajas, dado que, si bien el peso del "yo estuve allí" vence en un lado de la balanza, la relación pasional, el exceso de proximidad, puede deformar las cosas amadas y las odiadas equilibrando o alzando el otro platillo. Bastará que se entienda entonces esta segunda deformación como rasgo de una historia de vida de otro cabanyalero cualquiera, o acaso inevitable relleno interesado en la memoria de un espacio vivido. Como quería Park, tal vez esto suponga hurgar un poco en el inconsciente de un barrio. Tant se val.

Ese punto ciego abarca aproximadamente desde la muerte del dictador Franco -momento en que, más o menos, le viene a uno la memoria, es decir, momento en que uno "cae" ahí-, y el despegue del urbanismo neoliberal feroz con el PEPRI, ya al final del siglo XX. Hemos afeado a conciencia el bello título del libro editado por la antropóloga Beatriz Santamarina dedicado al Cabanyal: "Hijos del mar, hijos de la tierra" -que a su vez cita a una vieja cabanyalera: "Aci tots som fills de la mar o fills de la terra"-, para sugerir que

\footnotetext{
1 Cf. Blasco Ibáñez, Vicente, 1898.

2 El PEPRI "Pla Especial de Protecció i Reforma Interior del Cabanyal”, defendido por las fuerzas conservadoras españolas. El 24 de julio de 1998 el Pleno del Ayuntamiento de Valencia, con mayoría absoluta del partido conservador PP, encarga su redacción a los técnicos de AUMSA (“Actuaciones Urbanísticas S.A.”) y el 26 de febrero de 1999 el Ayuntamiento aprueba el anteproyecto. Suponía la expropiación y el derribo de 1650 viviendas, casi un tercio de ellas declaradas Bien de Interés Cultural por el Ministerio de Cultura en 1993.

3 Nos permitimos usar "Cabanyal" como sinécdoque más antiguo para referirnos a las tres partidas o poblados que constituían el Poble Nou de la Mar: Canyamelar, Cabanyal y Cap de França.

4 Cf., por ejemplo, Santamarina, Beatriz, 2009, 2010 y 2014b; Bodí Ramiro, J. y López Nicolás, M, 2009.
} 
ese punto ciego se rellena con un cierto brutalismo; un brutalismo que iba más allá del que según Blasco Ibáñez era característico de los huertanos y los cabañaleros y que tenía más que ver con un mundo ya sucio de costrosas grasas industriales y con la frustración de un barrio que parecía si no aislado sí olvidado ${ }^{5}$, un mundo que "iba a la suya", sin futuro y con un pasado en ruinas, y que personificamos o condensamos -a muchos barios de presión-en Pepica la Pilona, un personaje clave del barrio que aparecerá aquí y allá, inopinadamente como ella solía hacer, a fin de traernos a la tierra de nuevo.

Para pincelar el viejo Cabañal nos permitiremos usar tanto los testimonios y documentos a nuestro alcance como la obra valenciana inicial de Vicente Blasco Ibáñez. Ningún adulto sano del barrio dejó de aupar el ataúd del escritor en su recorrido desde la Estación del Norte al cementerio de Valencia, cuando sus restos fueron traídos de Francia -donde había fallecido pocos años antes-, durante la Segunda República. Lo que vinculaba al autor con los Poblados Marítimos no era sólo que Flor de Mayo (Blasco Ibáñez, 1995) novela folletín editada por entregas en el periódico Pueblo, que dirigía a la sazón, retratara la vida de los pescadores del Poble Nou de la Mar, y tampoco el que a principios de siglo se construyera en la playa de la Malvarrosa su chalet de estilo pompeyano, sino que su figura había impregnado la vida política del Cabañal desde finales del XIX hasta la Guerra Civil, que no puede entenderse sin el "blasquismo" de sus habitantes, casi un sinónimo de "levantisco" o "revolucionario".

Entre Flor de Mayo y La Barraca, en 1897, el Poble Nou de la Mar, el Cabanyal, deviene, en contra del deseo de sus habitantes, un distrito de Valencia ${ }^{7}$. La cuarta novela valenciana de Blasco Ibáñez -que aunque cuenta los reveses de una venganza también relata las inescrutables consecuencias de un desahucio, el del Tío Barret y su familia- puede reflejar el ambiente huertano del viejo barrio, aislado por los huertos y las acequias del resto de la ciudad. Así nuestra visión de paralaje lo es en un segundo sentido: vemos el Cabañal de los 70 y los 80 a la luz del "viejo Cabañal" y viceversa. Quisiéramos contar qué es lo que ya no existía o estaba a punto de desaparecer, qué fuerzas nos vinculaban todavía, si es que las hubiera, y qué fuerzas estaban a punto de convertir el antiguo pueblo de pescadores en uno de los paisajes más desolados de la "Valencia global". Y como no hay niños en la memoria, ni magdalenas, sin inconsciente a flote, nuestro trabajo implica una visión de paralaje en un tercer sentido, el que entraña el contraste entre la mirada del niño que pensamos que fuimos, y la del adulto que con más o menos tesón pretendemos personificar. El espacio vivido en la memoria es puesto, pues, entre espejos paralelos.

\section{Sociedad pequeña, sociedad densa}

En los años setenta del siglo pasado vivían en el Cabanyal cerca de treinta mil almas. Severamente castigado durante la Guerra Civil, fue recibiendo población del interior atraída por el trabajo industrial, no sólo portuario, de Valencia. Entre los años cuarenta y los setenta se construyen en el barrio unas 6.000 viviendas, más la mitad de las que contiene hoy día: en una sola década de desarrollismo y de éxodo rural, en los sesenta, se edificaron casi el doble de viviendas que las construidas en los últimos 30 años, -incluyendo en éstos el boom inmobiliario de los noventa ${ }^{8}$, dando entrada en el barrio a oleadas de trabajadores migran-

5 Como veremos al final de este artículo, en realidad los poderes públicos nunca se olvidaron del Cabanyal, sino que promovieron su descapitalización por acción (a veces directamente mafiosa) u omisión...porque había quienes sacaban renta de él.

6 Según Beatriz Santamarina, "la primera etnografía del Cabanyal".

7 Lo que fue un caso más de las políticas expansionistas de las ciudades de entonces (Cf. Boira, Josep Vicent y Serra, Amadeu, 1997). En 1870 Valencia se había anexionado Patraix, por ejemplo.

8 Según datos de la Oficina d'Estadística del Ajuntament de València, entre 1961 y 1970 se construyen en el barrio 3.154 viviendas; entre 1981 y 2011, 1657 viviendas. 
tes, sobre todo castellanomanchegos y extremeños, o del interior valenciano, y absorbiendo también la necesidad de vivienda de la que había sido la primera generación de niños de la posguerra, muchos de ellos hijos de desplazados que fueron llegando a los Poblados Marítimos $^{9}$ al terminar la Guerra.

Se construyeron bloques de edificios -en los años cuarenta de tres o cuatro alturas, más tarde, en los sesenta, de hasta ocho plantas- muchas veces sin ningún tipo de previsión urbanística, comiéndole hectáreas a la huerta, junto a una acequia abierta, frente a una vía del tren de transporte de carbón o acaso a la vera de alguna escombrera, sin que los poderes públicos se encargaran de planificar y prever necesidades de escuelas o ambulatorios para una chiquillería que en poco tiempo se colaría por todas las grietas del barrio, se haría dueña de la calle y exploraría los secretos de la huerta y de la playa. Recién muerto el dictador:

"La reunión constitutiva de la Junta del Distrito Marítimo se celebró con mucha cautela en una pequeña parroquia de la calle Poeta Más y Ros, bajo el amparo del párroco Paco Vizcarra. [...] El manifiesto fundacional afirmaba que la Administración consideraba a los vecinos de los barrios populares como ciudadanos de segunda categoría y había propiciado su crecimiento desordenado ${ }^{10} "$ (Sanchís Pallarés, 2009: 174).

De modo que el barrio adquirió esa peculiar fisonomía que todavía se ofrece hoy a la mirada: un paralelepípedo de unos dos kilómetros y medio de largo frente al mar, cruzado por travesías más cortas, dando un trazado en rejilla, la trama histórica de las antiguas barracas de pescadores pero extendida hasta tocar la Malvarrosa, con casas construidas en los años veinte o treinta, normalmente de dos plantas y fachadas con viejos portones de madera decoradas en un estilo modernista popular ${ }^{11}$ mediante mosaicos o collages de azulejos y cerámica verdes o azules, junto a bloques de edificios típicos de los años cincuenta a los setenta, romos, austeros y sencillos, habitados en su mayoría por trabajadores industriales. Dos rasgos, sin embargo, se irán haciendo comunes a ambos tipos de vivienda: su orientación hacia el este, hacia el mar y el color burdeos profundo o negro que exhiben los muros exteriores en sus lados norte-sur.

Cabanyaleros nacidos en los albores de la Guerra seguirían viendo, en pleno siglo XXI, ese desembarco de gente más joven y desconocida, que ocupaba edificios altos donde antes había un parche de campo, un solar, o acaso alguna barraca abandonada, que no hablaban valenciano y carecían de vínculos con el mar, la huerta o la ciudad, el punto de inflexión en que se pierden los rasgos comunitarios del viejo Cabanyal, su identidad folk:

"Els canvis més dràstics al Cabanyal [explica Miquel, es van produir als anys 60-70], de la nit al matí tot desaparegué, la gent tancant portes perquè aparegueren els lladres. Es començà a construir, afonar cases, pisos, finques, i tancar portes perquè la gent se colava dins a robar. Aparegueren les motets, entrà el pànic i tot desaparegué... «isquérem de la dormidera d'estar antics...»" (Santamarina, 2010: 225).

\footnotetext{
9 Los Poblados Marítimos de Valencia lo integran, en la vega izquierda, Nazaret, y en la derecha, el Grao, el Canyamelar-Cabanyal-Cap de França, y la Malvarrosa.

10 O, en términos de Reig-Picó: "Se cometieron los mayores atropellos urbanísticos, se permitieron edificios con alturas prohibidas por las ordenanzas municipales, zonas verdes fueron calificadas como terrenos edificables, se autorizó la demolición de edificios históricos y se hizo la vista gorda ante la edificación de barrios enteros carentes de los más elementales servicios" (Cf. Sanchís Pallarés, ibid.: 167).

11 "[...]una interpretación libre y original del modernismo creado por la clase popular; por pescadores [...], reflejo de aquella burguesía que veraneaba en el Cabanyal”, según Trinidad Simó.
} 
En efecto, los niños del baby boom, nacidos aproximadamente entre los sesenta y el setenta y cinco crecieron en una sociedad que ya no era un "grupo de parientes"; por mucho que siguiera habiendo botiguers conocidos como el Tío Paco o el Tío Pepe, y personajes célebres identificables por todos, como la Pilona o el Mona, eran inevitables los contactos efímeros en cuanto te movieras un poco por el área. No obstante, como muchos de los desplazados provenían del interior y carecían, en general, de unos estudios primarios completos debido a la miseria de la posguerra, no eran infrecuentes los "catetos urbanos" y las familias extendidas en las que los abuelos mantenían todavía una autoridad sólida -común a esta generación de niños es un respeto casi reverencial hacia los yayos, mayor que hacia los propios padres-.

El Cabañal de Blasco Ibáñez es una sociedad poco densa ${ }^{12}$ en la que no existe la posibilidad del andar libre y errante del flaneur: aquí "hay que saludar". La presión del grupo se ceba en los individuos no sólo en forma de motes, cizañeos y venganzas, sino también determinando su estatus desde el nacimiento:

“[...] ellos nacían allí; no veían más sustento que el mar; se agarraban a sus pechos para siempre” (Blasco Ibáñez, 1898: 353).

Pero este "determinismo ambiental en la relación medio ambiente-hombres" (Cfr. Boira y de la Calle, 1987) choca con el naturalismo del autor, y por eso la naturaleza de cada cual acaba imponiéndose sobre las reglas sociales y sobre los efectos de la división del trabajo en el carácter de las personas, ciertamente marcados en el mundo de Blasco Ibáñez -el botiguer de Arroz y Tartana, el pescador de Flor de Mayo, el de la Albufera en Cañas y Barro o el huertano de La Barraca son tipos humanos- $-{ }^{13}$ Una de las consecuencias de ese naturalismo es que la lucha de clases tiende a sustituirse o acompañarse por envidias de clase y luchas intraclase, debidas justamente a los desajustes que la peculiar naturaleza de un personaje o personajes provocan en el nomos, en la costumbre.

Tal presión de grupo ya no existía en los años setenta, al menos en la producción de los tipos. Todavía los remendaors en la calle de José Benlliure se inclinaban las mañanas de los sábados sobre las redes azules a lo largo de la acera y en la playa quedaban algunos secaderos de pescado, pero la pesca ya estaba reducida a un sector muy marginal y terminaría desapareciendo del paisaje del barrio a lo largo de los ochenta; a la industria, por su parte, le quedaba una década para empezar su reconversión, por lo que el mundo parecía dejar una cierta libertad a los niños en lo referente a elegir su destino. Pura ilusión infantil, claro.

\section{Sociedad aislada, sociedad conectada}

Un siglo después de la anexión al Ayuntamiento de Valencia, los vecinos del barrio seguían diciendo que "iban a Valencia" cada vez que se desplazaban al centro de la ciudad. Ciertamente los límites del barrio en los tiempos de La Barraca estaban mucho más marcados, siquiera sea porque la huerta, que lo separaba del resto de la ciudad, se manifestaba en su esplendor, ocupando la mitad de lo hoy urbanizado, en una sociedad entonces dominada por el sector de la agricultura ${ }^{14}$. Las acequias discurrían al descubierto, muchas veces con su tufo pestilente, anchas como para requerir puentes: Riuet, al Sur, dando al Grao, entonces

12 No superando entonces los ocho mil habitantes en todos los Poblados Marítimos.

13 Como dice Beatriz Santamarina: “[...] hay que señalar que Blasco Ibáñez nos presenta a unos personajes estereotipados". (Op.cit.: 24).

14 En 1900, "un $43 \%$ de los activos de la capital trabajaban en el sector primario"; en los años cincuenta Valencia se convierte en una sociedad de servicios, superando este sector por primera vez a la industria. Para entonces, las labores agrícolas se habían reducido hasta ocupar a un $10 \%$ de trabajadores. (Cf. Boira, Josep Vicent y Gaja, Fernando, 1994). 
la única entrada y salida a la ciudad y, por el criterio de la proximidad al centro, de más alto estatus socioeconómico; La Cadena, al Norte, lindando con los campos de malvarrosas del doctor Robillard. El mar al Este y la huerta al Oeste, jalonada por lo que entonces era la vía del tren de Sagunto, que la atravesaba de Norte a Sur y encerraba al barrio entre ella y la playa.

Vías, huertas, cequias y playas servían de puntos de referencia para los límites del barrio y en cierto modo para su aislamiento. Y sin embargo todas las mañanas, en los tiempos de Blasco Ibáñez, una fila interminable de trabajadores marchaba por el Camino del Grao (hoy Avenida del Puerto) hacia el centro : huertanos con sus tartanas repletas de fruta y verdura, pescadores con las suyas de pescado y de ordinarias peixcateras, o las más pobres a pie con sus banastas al hombro o a la cadera, llauraoras con su vaca para vender la leche por el centro casa a casa, panaderos, todos a pagar su cuota en el fielato del Puente del Mar; y los nuevos obreros industriales, hombres y mujeres, hacia las fábricas de gas, de tabaco, de seda. Los cabañaleros se traían del centro los beneficios de las ventas o los salarios muchas veces en forma de productos industriales. No olvidemos tampoco la tendencia de la burguesía a construirse chalets en primera línea de playa, como hizo el propio Blasco Ibáñez, desde finales del XIX. Difícilmente pueden considerarse aisladas dos zonas que funcionan como vasos comunicantes ${ }^{15}$.

Aunque ya no consistiera en un intercambio diario de bienes básicos, la comunicación con el centro, y por tanto las vías para ello, eran mayores en los años setenta del pasado siglo, cuando el automóvil empezaba a ser el rey de las calles. Las acequias que delimitaban el barrio, excepto la de La Cadena - ésta casi en su totalidad-, habían sido cubiertas, y en su lugar se extendían avenidas que la conectaban con el centro atravesando las vías del tren de Barcelona (el de Sagunto de Blasco Ibáñez) mediante pasos a nivel que a veces conseguían retener a miles de vehículos en una y otra dirección durante ratos interminables. Y también la atravesaba el trenet, cuya vía corría paralela a la cequia de La Cadena, un tren de vía estrecha que nosotros llamábamos con el oxímoron "tren de madera", porque venía e iba a Pont de Fusta ${ }^{16}$-donde, al salir de la estación, como si hubieras vivido una extraña elipsis, te golpeaba la panorámica de las Torres de Serranos por encima del pretil de piedra, pulida por el tiempo, del viejo cauce-, y porque todavía a principios de los setenta los asientos, el suelo y las paredes, los vagones del trenet, parecían los de un barco de listones barnizados y resinosos. Todos los días, a las seis menos cuarto de la mañana, el ferroviario hacía sonar la campana de la estación de La Cadena y un tren que llegaba del centro se cruzaba con otro que venía del puerto, y así exactamente cada quince minutos entre la madrugada y la medianoche, año tras año hasta enero de 1991.

De forma que la frontera noroccidental del barrio la trazaban dos líneas precisas: una de Norte a Sur, la vía del tren de Barcelona, y otra de Este a Oeste, la del trenet de Pont de Fusta. El punto en que se cruzaban ambas vías era, por antonomasia "El Cruce". De nuevo, aquello que en cierto modo aislaba al barrio, era también lo que lo comunicaba -el proyecto de los setenta de hacer entrar la autopista de Barcelona por la playa y levantarla por encima del puerto participaría de este mismo espíritu-.

El "tren de Barcelona" podía ser un mercancías infinito o un velocísimo talgo de aluminio y acero que parecía ir y venir de otro mundo y que apenas dejaba adivinar las caras de la gente asomada a las ventanillas fijas. El trenet, en cambio, pertenecía al mundo de acá, lo usabas, circulaba con la suficiente lentitud como para poder tocar a la gente asomada a unas ventanillas macizas de pino verde que se sostenían -por algún extraño milagro de la Física, dados los vaivenes tremendos del mecanismo-, sobre el marco superior, encima de las cabezas, o que se agolpaba en verano fuera de las puertas abiertas, agarrada a cualquier saliente.

15 Cf. Boira, Josep Vicent, 2005 y Sorribes, Josep, 2010.

16 "Puente de madera", en catalan. 
La huerta abrazaba el recorrido de las vías con tal intensidad que en algunos momentos parecía engullir completamente al trenet, envolviéndolo en una bóveda oscura, fresca, olorosa y húmeda de madreselvas, zarzamoras, trepadoras, o chíncholes que impregnaba los cuerpos hasta que, pasados La Cadena, el Polit y el Boat, el olor del salitre y los salazones sustituía de súbito al de la vida vegetal de la huerta.

Más que dos trenes, eran dos ritmos de tiempo y dos dimensiones de la vida -la desconocida y la conocida, la moderna y la tradicional-, y del espacio -el eje Norte/Sur y el eje Este/ Oeste-, los que se cruzaban en un paso a nivel con barrera rodeado de cañaverales huertanos, marcando con precisión en el mismo punto el límite noroccidental del barrio y un nodo para las bandas. Y fue un ritmo del tiempo aplastando al otro, o una expresión catastrófica del principio marxista de la aniquilación del espacio por el tiempo, lo que nos fue dado vivir una tarde, a la vuelta de las vacaciones, un 9 de septiembre de 1977, cuando un talgo Mare Nostrum procedente de Barcelona embistió en el "Cruce", -cuya barrera no bajó quién sabe por qué-, a un trenet Fabiolo que venía de Valencia, tranquilo como siempre, arrastrándolo doscientos metros hacia el Sur como si fuera de cartón. Seis personas murieron y más de veinte resultaron heridas; desde entonces la exigencia de enterrar las vías del tren fue elevada a clamor político. Por una ironía del destino,-que hace tiempo es la política-, cuando la vía del tren de Barcelona fue definitivamente soterrada a su paso por el Cabanyal, en 1991, el trenet también dejó de funcionar.

La muerte de varias personas en el "Cruce" ocurrió un mes despúes de la de Paquito Borrás por bañarse cerca de la desembocadura de la cequia de Vera, en el límite Norte de la Malvarrosa, confirmando con ello la leyenda urbana, alimentada sin saberlo por la historia del hijo pequeño de Batiste en La Barraca, de que si caías en la cequia de Vera, caudalosa como un río y podrida como un muladar, contraías la peste. Aquéllas eran muertes debidas al olvido en que ya vivía un barrio que parecía dejado de la mano de Dios, como un apéndice más elemental, más telúrico, de la ciudad, como un tubérculo agarrado a sus raíces o una extraña neoplasia de Cronnenberg.

Uno de los argumentos que se dieron a favor del derribo de 1650 viviendas que decretaba el urbanismo neoliberal del PEPRI fue la conexión histórica del barrio con la ciudad. Sin embargo, por aquel entonces, en 1999, ya se habían producido tres grandes cambios que lo integraban definitivamente a Valencia: primero, el soterramiento de las vías del tren de Barcelona y la urbanización de su perímetro propiedad de RENFE; en segundo lugar, la recalificación de suelo de huerta como urbanizable -el retiro de la huerta- y la sustitución del trenet de madera por dos líneas de un moderno tranvía tipo LUA flanqueadas por dos calzadas de cuatro carriles que llegan casi al mar; en tercer lugar, la progresiva edificación de la Avenida de Blasco Ibáñez - la avenida que en el PEPRI tenía que atravesarla-, hasta las puertas del barrio, donde en el 91 se inauguró la estación parcialmente subterránea del Cabanyal.

Sin embargo, mientras se allanaban los límites y se integraba en la ciudad, el barrio perdió casi un tercio de sus habitantes, quedándose por debajo de las veinte mil almas en sus peores momentos, degradándose de año en año, como si la promeusse de bonheur que representaba la conexión física largamente esperada con Valencia significara al mismo tiempo, y por alguna razón inescrutable, su propia destrucción.

\section{Salvajismo, barbarie, civilización}

Como una corroboración inconsciente de aquella teoría de la recapitulación de Stuart Hall que hacía de la juventud un atavismo filogenético, la chiquillería del baby boom de la zona Norte del Cabanyal, el Cap de França, formaba hordas de cazadores ${ }^{17}$ sutiles/recolec-

17 Neil Smith advirtió del uso de las metáforas de la frontera y de la selva en los proyectos gentrificadores, animando a las clases medias profesionales a "aventurarse" en terrenos todavía peligrosos. No obstante, como 
tores en las hendiduras de un mundo que pretendía civilizarlos, a veces, a palo limpio, y que se movían más por la alegría de la exploración que por la melancolía del flaneur. Armados de tirachinas y bolsas de "chungos" - pequeños segmentos de un duro y acerado junco silvestre que, doblados, servían de proyectil-, los bolsillos llenos de piedras, -o tal vez bolas de abrojo o de falso plátano, dependiendo de la intensidad del peligro esperado-, enfilábamos la vía del tren de Barcelona como el curso de un río tropical que sirviera siempre de punto de orientación ante cualquier desvío por la selva, decidiéndonos entre la huerta y sus alquerías perdidas y los térrains vagues o los paisajes industriales de más allá del Beteró.

El llaurador de Blasco Ibáñez, sin embargo, era ya un tipo antropológico inexistente en un barrio todavía cercado por la huerta en los setenta, -aunque conservaban en sus barracas o alquerías algunas tradiciones como la de la escopeta en la puerta, por la forma en que a veces nos disparaban con cargas de sal cuando invadíamos sus propiedades-. El desarrollismo le había comido, entre 1956 y 1977, unas 5000 hectáreas a la huerta periurbana de Valencia; luego, tras un período de ralentí en que los niños del baby boom crecieron, volvió el ímpetu urbanizador comiéndole otras tantas. En total, según el geógrafo Ángel Soriano, en los últimos 50 años Valencia pierde cerca del $64 \%$ de un paisaje que ya se considera en riesgo de extinción ${ }^{18}$.

Como cazadores sutiles/recolectores habíamos mimetizado formas y hábitos del objeto de nuestras cuitas: un no sé qué inhumano y cruel con los bichos, una manía por fabricarse nidos, madrigueras y escondites entre los cañares; y esa propensión a colarse por todas partes y a cogerlo todo de cualquier lado, cual hormigas. Como insectos, -hemimetábolos u holometábolos, todavía no lo sabíamos-, nos colábamos en el cuartel de la Remonta, en la piscina de las Arenas, en el fútbol y en el Instituto para jugar al fútbol; te colabas en los cines, en los hospitales y en los trenets, en el puerto y las barcas de la playa; te colabas en las huertas, en las casas abandonadas o en construcción: no había cercado o valla vieja que no fueran horadados, trepados o escalados. Como cazadores, disfrutábamos de la sobreabundancia de bichos que poblaban la huerta y la playa; como recolectores, espigolábamos, nos alimentábamos con frutas o mazorcas por el camino, o recogíamos los restos y desechos que la sociedad dejaba en los intersticios abandonados, sobre todo cartón y chatarra, $-\mathrm{y}$ tres hurras por una bobina de cobre, suficiente para pagar la entrada al cine- que luego vendíamos al chatarrero.

Por aquel entonces una buena parte de la playa estaba cubierta de hierba, y entre ésta y la arena vivía, desde décadas atrás, una colonia de escarabajos peloteros de torso negro laqueado; con una devoción casi egipcia, en vez de cazarlos los observábamos trabajar con esa precisión de diminutos proletarios que exhibían al arrastrar las bolas de estiércol hacia sus nidos, dejando toda la superficie de la arena escrita en extraños caracteres cuneiformes con los movimientos de sus patas. Las bolas de estiércol se las proporcionaba alegremente la caballería de un Depósito de Sementales, el Cuartel de la Remonta, construido por Franco al terminar la guerra en lo que era una vieja alquería del Cap de França, tal vez para echarle un ojo de cerca a ese barrio de pescadores republicanos que tantas "regiones devastadas" se había ganado del 37 al 39.

Si ya en la Primera Guerra Mundial la Caballería se había convertido en un Orden exó-

el mismo Smith recuerda, desde Los mohicanos de París de Eugène Sue en el XIX, pasando por la Jungla del asfalto en el XX, el imaginario urbano se ha nutrido desde hace dos siglos de tal comparación. El indio en la selva descifrando los signos que los demás no entienden es uno de los perfiles o facetas del flaneur.

18 Cf. Soriano, Víctor, 2015. Según el profesor Thomas Glick, ello sería consecuencia de los intereses económicos de la clase conservadora junto con una población seducida por la ganancia a corto plazo -los precios de las hectáreas de huerta se duplicaban de año en año desde los 90, hasta que el pobre (ahora rico) huertano no tenía mucho que elegir entre "plantar cebollas o plantar ladrillos"-. Según el Informe Dobris (1995), de la Agencia Europea del Medio Ambiente, la huerta periurbana de Valencia es uno de los paisajes urbanos que está cerca de la extinción, como la de Palermo o la "Ghuta" de Damasco. 
tico, en los años setenta era un espectáculo ver -y sobre todo, antes, escuchar el lejano resonar de las herraduras sobre el pavimento de-casi un centenar de caballos al trote o al paso, yendo o viniendo de la playa, donde se ejercitaban y podían correr a rienda suelta, o ramonear sobre la pradera de grama. No fue, pues, casualidad que el sonido de los cascos de los équidos desapareciera más o menos al mismo tiempo que el zumbido de los escarabajos peloteros en la playa del Cabanyal: tras la muerte del dictador, el III Depósito de Sementales fue prácticamente abandonado por el ejército, y durante uno años fantasmales el viejo caserón -un edificio blanco y rectangular de dos plantas y de unos sesenta metros de largo, espartano como todo cuartel, que en gran parte ya se venía abajo, con un patio interior enorme y abierto entre las caballerizas y lo que debían ser habitaciones para los soldados, donde se se erguían dos majestuosas moreras-, permaneció custodiado por cuatro o cinco soldados que reemplazaban pasados unos meses. Como en un castillo encantado y vigilado por duendecillos con tridente, los niños nos colábamos por una de las ventanas para coger hojas de morera con las que alimentábamos a los gusanos de seda en cajas de zapatos agujereadas, para lo cual teníamos que esquivar la vigilancia de los soldados y aprender las tres o cuatro salidas posibles, con distinto grado de peligrosidad, por las que podías escapar corriendo en caso de ser sorprendidos y perseguidos.

Aunque Valencia había sido una auténtica potencia en la industria de la seda mucho antes de alborear el siglo XIX, cuando el casco antiguo bullía de telares de velluters, lo cierto es que desde mediados de siglo le venía ganando la mano la sedería francesa, sobre todo la de Lyon, y en los tiempos de Flor de Mayo ya "en las barracas se había perdido la memoria de las cosechas del capullo": "ya no hay moreras en la huerta", recuerda un personaje de Arroz y Tartana. A pesar de esta decadencia, Roseta, la hija de Batiste, es una de las obreras que desfilaban por el camino del Grao para trabajar en una fábrica de seda, donde echaba los capullos en calderas de agua hirviendo en cuyo fondo la crisálida moría achicharrada a punto de completar su metamorfosis, para luego tener que despegarse de hilos larguísimos color caramelo que la cocción de los capullos dejaba al fondo del caldero.

La cría del gusano de seda, -un animal que, pese a todo nuestro laborar con él, entraba en la categoría de lo asqueroso, junto con los murciélagos, las ratas, las cucarachas y las babosas- no fue sólo una costumbre de los jóvenes cabanyaleros del baby boom, sino de varias generaciones en España. La práctica tenía una función pedagógica, pues permitía al niño experimentar y observar -así se solían llamar los libros de texto de ciencias: Observo y experimento - los milagros de la naturaleza. Pero también la sericultura infantil ahorraba a la generación vieja el tener que explicar ciertos temas sexuales considerados tabú por una sociedad pacata; y además inculcaba cierta disciplina sobre la vida y la muerte, los ciclos de la vida presentidos, las edades del hombre: tal vez nosotros debíamos cambiar, ser diferentes al salir del capullo, -los otros, los adultos, ya estaban hechos-, y, al final, morir. O, tal vez, como ocurría con los insectos hemimetábolos, como nuestros maltratados saltamontes, simplemente aumentaríamos de tamaño sin cambios traumáticos en nuestra identidad.

La desaparición de esas hordas de cazadores-recolectores a lo largo de los ochenta, en una sociedad que tendía al crecimiento cero, al retroceso fulminante de la huerta y al imperio del automóvil sobre las calles, fue acompañada de sus piezas favoritas: saltamontes, lagartijas -las reinas de las vías-, murciélagos, mariposas, mariquitas, mantis, arañas y libélulas, tellinas de la playa o cangrejos del espigón; y del olvido de sus armas: rastrillos armados en un palo de escoba para la orilla, cañas con alambres atados a una punta para los murciélagos, tarros para las arañas, chungos para los tirachinas y ballestas caseras o nunchakus torpes -que nosotros llamábamos "buchakus" por las películas de Bruce Lee- para encuentros con otras bandas. 


\section{Letrados o iletrados}

Los mundos de La Barraca y de Flor de Mayo son orales y tradicionalistas. Los niños van a la escuela mientras los padres puedan pagar al maestro cada semana y si no, sencillamente "se crían como las gaviotas" hasta que, bien pronto, tiernos todavía, les corresponde el trabajo que compete a cada sexo: tareas domésticas y distribución y venta para las mujeres casadas de la huerta y de la mar; ellos, a pescar o a cultivar la tierra. Aunque el trabajo en la fábrica, en una sociedad de una incipiente industria, no tiene marca de género, en un mundo cerrado de pescadores y de agricultores queda reservado para las hijas no casadas. A los ocho años, Pacualet, en Flor de Mayo, se empeña en embarcarse con su padre, quien consiente sin poner ninguna objeción a pesar de las protestas desesperadas de la abuela, la Tía Tona. Desoír las demandas de esta Casandra del Bou les llevará a la catástrofe.

Tanto los pescadores como los labriegos de Blasco Ibáñez manifiestan una desconfianza radical hacia la escritura, y por tanto hacia la ley escrita y todo el mecanismo funcionarial que la sustenta, desde el carabinero -el guardia civil- hasta el juez. Por este motivo en esos mundos la justicia se entiende todavía como venganza: "para aquella tierra no se había hecho la justicia de las ciudades" y precisamente para evitar la cadena de la violencia que arroja la venganza, -analizada tan bien por René Girard-, la huerta valenciana articula desde tiempo inmemorial un mecanismo jurídico intermedio entre la Ley del Estado y la Venganza de los hombres, entre la Ley Escrita y el escopetazo o el insulto: el Tribunal de las Aguas ${ }^{19}$.

Todos los jueves laborables, tras repicar a mediodía las campanas del Miguelete, ante la puerta ojival de los Apóstoles de la Catedral, hoy, en los tiempos de La Barraca y al parecer en los de Abderramán III, acuden a su cita los síndicos del Tribunal: "eran los amos del agua: en sus manos estaba la vida de las familias". Los siete ramales principales -hoy ocho- que derivan el agua del río Turia hacia las dos vegas, la izquierda o Sur -Quart-Faitanar, Mislata, Favara y Rovella-, y la derecha o Norte -Mestalla, Tormos y Rascanya-, dan el nombre a esos siete jueces vestidos de negro que, con "una majestad de labriegos ricos", suelen llegar rodeados de un cortejo de guardas de acequia para dirimir, con la autoridad que da la posibilidad de cortar el flujo del agua hacia una barraca, las disputas entre los huertanos. Sin papeles, sin firmas, sin policía, sin dilación de la pena: donde las palabras no se escriben, el ritual de los cuerpos debe sellarse con precisión en la memoria y el llauraor no puede evitar, a pesar de todo, enfrentarse a una entidad ajena, un "monstruo de siete cabezas".

El brutalismo es un rasgo típico del pueblo en su relación con la ciudad y de las clases bajas en su relación con las clases altas; el del Cabanyal poseía al menos cuatro peculiaridades históricas: primero, que los del barrio seguían considerándose un pueblo décadas después de su anexión a Valencia, y los del pueblo son tratados como "aprendices urbanos" en la ciudad; segundo, que el barrio se asociaba al uso del valenciano por parte de los autóctonos pescadores y labradores cuando la Valencia burguesa despreciaba como vulgar, -al menos hasta los años ochenta-, el uso de esa lengua; tercero, que los trabajos de la pesca y de la agricultura siempre han estado marcados en este respecto: ahí están los que cogen el pescado con las manos, los que los sajan, los que los meten en el hielo de las cajas de madera para el mercado, y los otros, los que se llenan las manos de esa tierra llena de boñigas para que el urbanita compre su bandeja limpia y plastificada; y cuarto, que existía una

19 Blasco Ibáñez se apropia de la idea del origen musulmán del Tribunal al recordarle "el jefe de la kábila sentenciando a los pies de su tienda". Según esta hipótesis, cuando en el año 1239 el rey Jaume I reafirma en el Fuero XXXV "las costumbres musulmanas en materia de regadío" se estaría refiriendo con ello al Tribunal de las Aguas, que se habría constituido en los tiempos de la construcción de la Alhambra por Abderraman III, rondando el año 960. Para apuntalar la hipótesis se suele mencionar también el hecho de que las sesiones se celebren en jueves y a los pies de la Catedral -la antigua Mezquita-. Sin embargo, el profesor Thomas Glick sostiene que el Tribunal sólo comenzó a funcionar como tal en tiempos de las Cortes de Cádiz, habiendo sido anteriormente una reunión ritualizada de sequiers. 
jerarquía espacial de brutalidad que la hacía disminuir conforme te aproximabas a la ciudad desde el Canyamelar y el Grao y la hacía aumentar cuando llegabas al Cap de França y la Malvarrosa:

"La gente del Grau era administrativa, gente de educación, gente de carrera, capitanes de barco, maestros de escuela, médicos, o sea que habían ido a la universidad, [...]. El Canyamelar era de clase media, la trabajadora que tenía un comercio, tenía una tiendecita, tenía un taller. Y el Cabanyal era lo más bajo, marineros" (Santamarina, 2010: 53).

En los años setenta todo este cuadro estaba muy desdibujado. Al secular desprecio de la burguesía hacia el valenciano se le unían décadas de represión franquista y miles de trabajadores castellanoparlantes que ocupaban bloques cada vez más altos desde los cincuenta. La escuela, la administración, los medios de comunicación, eran estrictamente en español y sólo una minoría de niños mantenía el valenciano como lengua familiar. Era inevitable oírlo en la calle, en las botigas, pero siempre era algo así, algo que oyes "al paso" y a lo que te acostumbrabas como si fuera una forma extraña de hablar la misma lengua que tú hablabas; desde la muerte del dictador, por otra parte, la actitud oficial y general ante el valenciano cambió rápidamente ${ }^{20}$. En segundo lugar, por mucho que se siguiera diciendo "ir a Valencia" para ir al centro, ya se había perdido completamente la noción de vivir en un pueblo. El barrio del Cabanyal pertenecía al Distrito 11 de Valencia, nadie lo llamaba ya "pueblo" y en quince minutos de trenet, veinte de bus o cuarenta de marcha a pie te plantabas en el centro. Además, como la pesca y la huerta eran ya actividades muy marginales en el barrio respecto al trabajo en la industria y los servicios, no se nos podía considerar, desde fuera, asociadas a ellas. En fin, esos bloques altos construidos entre los cincuenta y los sesenta a lo largo del barrio habían nivelado bastante el orden del estatus Norte/Sur, generalizando ese ambiente de trabajadores, industriales o de servicios y marginalmente huertanos ${ }^{21}$. Aunque el barrio había alcanzado un alto grado de autonomía funcional en los sesenta y los setenta, para las letras serias, las firmas, los papeles, las cosas administrativas, había que ir al centro.

20 La actitud de la burguesía valenciana hacia su lengua durante estos años es de un cinismo histórico. Franco ya se encontró con una sociedad en la que "hablar bien" significaba hablar en castellano: todos los huertanos y pescadores se cambiaban -más mal que bien- al castellano cuando se desplazaban al centro. Pero tras la muerte de Franco la derecha valenciana se encuentra con dos problemas: primero, que los valencianoparlantes votaban, y segundo, que los intelectuales asociados a la defensa de la lengua de los valencianos pertenecían todos a la izquierda nacionalista antifranquista -gente como Joan Fuster, Vicent Andrés Estellés, Sanchís Guarner, Raimon, Ovidi Montllor o Vicente Ventura-, lo que implicaba meterse en terrenos intolerables para ella; la solución a los dos problemas no dejó de ser ingeniosa: se inventaron un nacionalismo valenciano de derechas -el blaverismobasado en la idea de que la "lengua de los valencianos" largamente defendida por esos intelectuales de izquierda era en realidad el catalán -algo que se sabe en todas las facultades de Filología del mundo- y que detrás de tales afirmaciones sobre la lengua se escondía una maniobra política de colonialismo cultural catalanista. Pasados unos años, ya engañada la gente, cuando la burguesía valenciana había conseguido hacerse una imagen como defensora de una lengua que en realidad había despreciado siempre -algo que se pudo comprobar en la última Cridà de la alcaldesa Rita Barberá-, el blaverismo de la taroncheta se evaporó de la tierra y fue sustituido por el cosmopolitismo de la Ciudad de las Ciencias y del inglés(Cf. Benlloch i Calvo, 2013).

21 La clase trabajadora, entendida como aquélla que alquila su fuerza de trabajo por horas a un empresario, puede incluir desde el trabajador sin derechos que gana cuatrocientos euros al mes a aquél que gana cinco mil, desde el trabajador fordista industrial al postfordista de servicios. Ello ha servido tanto para justificar la insistencia en las "clases medias" en Sociología y Urbanismo como para cuestionar la importancia de las clases sociales en los procesos de gentrificación. En el Cabanyal de los setenta no se observaban grandes diferencias entre unos trabajadores y otros, lo que no quiere decir que no existiera una cierta heterogeneidad o diversidad fácilmente observable en la educación, el tipo de trabajo, el coche o la casa de las personas. En cualquier caso, no existía ningún hotel en el barrio, ni venían visitantes a verlo. 
No existían en él abogados o notarios, ni delegaciones ministeriales, y la biblioteca más cercana estaba en el Puerto.

Con los niños del baby boom se extendió la Educación General Básica ${ }^{22}$ antes incluso de imponerse la idea de la obligación estatal de garantizar una escuela gratuita de calidad, de forma que a la muerte del dictador los niños todavía pagaban, esta vez mensualmente y en una secretaría, una tasa en una escuela siempre católica que muchas veces era una casona o finca propiedad del propio director. Fue la última generación de niños educados a hostia limpia

Pero el Cabanyal en los setenta era brutal en otros sentidos. En primer lugar, en uno arquitectónico y urbanístico, porque se había llenado de bloques ásperos de viviendas sociales, de "adifisios" 23 que contrastaban con la coquetería de los mosaicos en azulejos y cerámica valenciana de las viejas casas de pescadores; en segundo lugar, era un lugar sucio ${ }^{24}$ (las acequias de La Cadena y de Vera seguían abiertas; la huerta y el campot se fundían aquí y allá, la basura se amontonaba en las calles por la noche desperdigada por gatos, perros y gaviotas; el suelo, pavimentado o no, repleto de vías vivas y muertas en las que medraban los arbustos y los bichos). En tercer lugar, era un lugar envejecido en sus rasgos más característicos, lleno de solares, de térrains vagues, lo que le daba el aire de un mundo abandonado y olvidado por los poderes de la tierra. En cuarto lugar, el barrio conservaba cierto ritmo de pueblo, como si al cruzar las vías del tren de Barcelona hacia el mar acaeciera una elipsis, el tiempo fuera más lento, las calles más de la gente, llenas de niños y de viejos -ausentes en el centro-, y hablando un valenciano especialmente bruto, apitxat, pronunciando bien fuerte las "chés", mezclado con el castellano en todas partes, como hacía Pepica la Pilona, uno de los típicos locos del pueblo, un personaje singularmente brutal al que algún horno de Pixavaques regalaba todos los días un pan de medio kilo que luego rellenaba con lo que le daban en las paradas del mercado.

\section{Sociedad segura, sociedad insegura}

Objetivamente, y a pesar de los coches que hoy son dueños de la ciudad, el barrio era más inseguro para la infancia en los setenta que en nuestros días, en parte porque las prácticas de las bandas infantiles rozaban muchas veces la temeridad en un entorno a veces crudo y salvaje, y en parte porque no existía la percepción del riesgo que una excesiva focalización en la infancia -"monitorización de la infancia", la llama Manuel Delgado-, nos ha dejado en las últimas décadas. Los niños, pues, iban a la calle sin temor, y sólo la noche, o ciertas zonas como esos descampados o térrains vagues que salpicaban el barrio,-llenos de dunas, maleza, desperdicios, restos de derribos, bichos, en los que los niños corrían libres,

\footnotetext{
22 Algo menos el Bachillerato y mucho menos la universidad. Entre 1964 y 1967 se construyen y abren, en el Grao, en medio de la huerta, el Instituto Sorolla, y en la Malvarrosa, en plena playa, el Instituto Isabel de Villena. Las instalaciones no daban para más de dos mil estudiantes en unos años en que la población adolescente podía cuadruplicar ese número en la zona.

23 Nos permitimos usar este ingenioso neologismo de José Ramón Lorenzo (Cf. Rubio, Jaime, 2014 y la página web de Lorenzo: Satán es mi señor: Blog de Arquitectura y urbanismo). Algo tiene que ver el brutalismo arquitectónico como estilo con todo lo que estamos contando. En el Cabanyal salían a la superficie todas aquellas cosas que en la ciudad estaban escondidas bajo la piel: sus acequias y sus desechos, su monte virgen, su carbón y sus trabajadores, como en esas láminas didácticas en las que los cuerpos aparecen exhibiendo todas las fibras de sus músculos.

24 Y más que sucio, oloroso. En contra de la recomendación de la Carta de Atenas, y tal como le gustaba a Jane Jacobs, el barrio estaba lleno de pequeños talleres, comercios o fábricas, de forma que a los olores elementales del pescado, las acequias y las huertas se les añadían los de las maderas y resinas cerca de las carpinterías, o el de la sangre de las radiales regadas con limón en los pequeños talleres metalúrgicos, el embriagador de la tostadora de café, del pan de los hornos o de los alcaloides del zapatero. En los "adifisios", sin embargo, siempre olía a refritos y pucheros. El centro de la ciudad era, por contraste, anósmico.
} 
se escondían a un paso de la urbe, de los edificios, y practicaban la exploración, la caza, la guerra o el escondite-, podían despertar en el imaginario infantil el miedo a los que eran algo así como los indios de las praderas: los gitanos. Siempre difíciles de contar, porque, más que raza, "gitano" designaba un estilo de vida, no debían superar el uno por ciento de la población del barrio. En el imaginario de los niños existían tribus amigas, que vivían con los rostros pálidos en el clot o en algún otro sitio y tribus hostiles, nómadas por lo general. Hartos de películas de vaqueros en los cines de sesión continua del barrio, temíamos y admirábamos a la vez esa vida libre -los gitanos no iban a la escuela-, al margen de la ley y sin embargo mafiosamente familiar, sin nuestro sentido público de la vergüenza pero con un orgullo de auténticos pieles rojas.

Entre finales de los setenta y principios de los ochenta una buena parte de esas hordas infantiles devino el enemigo público número uno: nosotros éramos ahora los temibles indios escalpadores. En unos tiempos en que la ETA mataba guardias civiles día sí, día no, la delincuencia juvenil en la calle se convirtió en el problema más preocupante para los españoles según las encuestas, generándose toda una mitología en torno a "héroes de barrio" encumbrados cinematográficamente como el Vaquilla, el Pirri o el Torete, con todos sus equivalentes anónimos en España. Existe en Valencia, sin embargo, un cierto discurso urbanístico bastante complaciente con aquellos años:

“Entre los años 1979 y 1991 Valencia contó con gobiernos [...] que, sobre todo en la primera mitad de los años 80 , impulsaron una política redistributiva, en línea con lo observado en otras ciudades españolas" (Díaz Orueta, 2010: 3).

El caso es que cuando se inauguraron los dos primeros glolugares de la Valencia del espectáculo, el Palau de la Música (1986) y el IVAM (1987), en tiempos de dominio absoluto del PSOE en el Ayuntamiento y la Generalitat, -mientras el glamour del País Semanal iba sustituyendo a las chaquetas de pana-, el barrio ya estaba estigmatizado y perdía población a raudales: no había taxi en la ciudad que se atreviera a llevarte al Cabanyal por la noche y en la Malvarrosa se habían constituido las primeras -y vergonzosas-patrullas ciudadanas de España. La venta y consumo de droga, que siempre van unidos al proceso de degradación de los barrios en general, en aquellos años de "inocencia" diezmó sobre todo a la parte más vieja del baby boom, la nacida entre finales de los cincuenta y principios de los sesenta; los más jóvenes los vimos convertirse en escoria humana, como si el agua de fuego hubiera de servir a un mismo tiempo para sellar con un muro de olvido la falta de perspectivas, de reconocimiento, de seguridad, que presentaban el espacio decadente del barrio y una sociedad en crisis de reconversión industrial y paro galopante. Una década después habrían muerto casi todos.

Y mientras la miseria y el SIDA hacían estragos, un frente anti-yonki surgía asociado a otro ritmo de vida y a otras drogas, pero a la misma clase de población con diez o quince años menos: los pastilleros, que pasaron del enganche diario al enganche de fin de semana, de la heroína-basura al éxtasis y del deambular de zombis a una aparente normalidad de lunes a viernes. Constituyéndose en el brazo armado de las patrullas ciudadanas, acabaron controlando el uso de la droga en el barrio a lo largo de los noventa.

\section{Notas sobre la gentrificación del Cabanyal}

Escribiendo estas líneas, aparecen en los diarios de Valencia noticias alarmantes sobre la okupación de decenas de viviendas en el Cabanyal por grupos de okupas organizados según una disciplina casi militar, asesorados, preparados, y algunos hasta "de clase alta", que militan contra la gentrificación del barrio ${ }^{25}$. Esto resulta extraño por varios motivos, no

25 Cf. El Diario Levante, el 30 de mayo del 2016: “Grupos organizados «okupan» el Cabanyal con planos y 
sólo por sugerir que los ricos andan ahora okupando chabolas, sino por cómo se utiliza en un nivel popular y periodístico un concepto hasta hace bien poco especializado del urbanismo, y sobre todo porque no se entiende muy bien que sea precisamente tras el triunfo de las fuerzas de izquierda en el Ayuntamiento y Generalitat valencianos y la consiguiente paralización del PEPRI -el gran gentrificador-, cuando los potencialmente desplazados claman más contra la gentrificación del barrio. Vayamos por partes.

Desde que Ruth Glass utilizara el concepto en 1964 -con "el lenguaje pintoresco de la renovación residencial", según Neil Smith- para referirse al desplazamiento de trabajadores en Islington por individuos de clase medio-alta, la "gentrificación" no sólo ha devenido uno de los conceptos estrella del Urbanismo y la Sociología, sino que el fenómeno "se ha hecho omnipresente en todas las zonas urbanas deprimidas" del mundo y ha dado forma a unos paisajes urbanos mediante mecanismos que se repiten por el planeta entero: el Soho, Harlem, o el Lower East Side de Nueva York, Birmingham, Glasgow, el Marais de París o Prenzlauer Berg en Berlín, la Barceloneta, Gràcia o Poble Nou en Barcelona, Chueca y Malasaña en Madrid, Ruzafa o El Carme en Valencia, o la Ría de Bilbao.

Como concepto estelar, el de "gentrificación" ha pasado por sucesivas gigantomaquias: en torno a su definición, en torno a sus causas, y -a partir de los noventa sobre todo-, respecto a su valoración moral y política. Aunque las dos primeras discusiones parece que han terminado por integrarse en una teoría unificada, no ocurre así con la tercera, apareciendo cada vez más defensores o apologetas de un concepto que en los ochenta era esencialmente crítico.

Sin querer contribuir a esta gigantomaquia, para hablar de la "gentrificación" del Cabanyal distinguiremos entre un sentido estrecho del concepto -"gentrificación estrecha", en adelante- y un sentido amplio -"gentrificación amplia"-. El significado estrecho puede ser:

“[...] el proceso por el que barrios pobres y proletarios, ubicados en el centro de la ciudad, son reformados a partir de la entrada de capital privado y de compradores de vivienda e inquilinos de la clase media (barrios que previamente habían sufrido una falta de inversión y el éxodo de la propia clase media)" (Smith, 1996: 75).

En sentido amplio, la gentrificación se llega a entender como "la producción de espacio para usuarios más ricos" (Jason Hackworth). Beatriz Santamarina hace un uso amplio del concepto:

"Entendemos por proceso de gentrificación no sólo la renovación residencial (el desplazamiento de los moradores de un lugar por la ocupación del espacio de otros nuevos con mayor poder adquisitivo) sino también las transformaciones sufridas, en los últimos años, en las dinámicas de crecimiento urbano (globalización, consumo, turismo, mercantilización del ocio, etc.)" (Santamarina, 2009: 917).

En relación a su sentido estrecho, no puede decirse que el Cabanyal sea un barrio "céntrico", como Ruzafa o Velluters, aunque ello deje de ser importante en tanto que el propio Neil Smith reconoce que una de las características de la última oleada gentrificadora a partir de los noventa-la tercera después de la de la postguerra mundial y la de los años setenta-, es su expansión y dispersión geográfica; por otro lado, el crecimiento tentacular de la ciudad de Valencia mediante nueva construcción (por Campanar o hacia el Saler) ya había llegado muy lejos del centro a principios del siglo XXI, bastante más lejos que el propio Cabanyal

manuales para entrar en las viviendas abandonadas", por José Parrilla. 
-lo que daría que pensar sobre la relación entre el "retorno a la ciudad" y la seguridad y rapidez de la tasa de retorno del capital-.

Lo más importante de la gentrificación estrecha es la conexión que establece entre degradación, desvalorización previa de una zona y la valorización o recapitalización posterior. La desvalorización, la degradación, pueden ser características naturales inevitables de los seres vivos, -al menos, por ahora-, pero no lo son de las construcciones humanas -al modo del barco de Teseo, rehecho tabla a tabla- ni, por tanto, de los barrios:

"El deterioro de los barrios constituye el resultado de decisiones privadas y públicas de inversión claramente identificables" (Smith, 1996: 119).

Se sabe que Smith trató de darle al proceso una apariencia de ley con la hipótesis del diferencial de renta, según el cual la gentrificación ocurre cuando la diferencia entre la renta actual capitalizada del suelo y la potencial (lo que se podría sacar aprovechando al máximo las condiciones actuales):

“[...] es tan grande que los promotores inmobiliarios pueden comprar a precios bajos, pagar las costas de los constructores y obtener ganancias de la restauración, [...] pueden pagar los intereses de las hipotecas y los préstamos y luego vender con ganancia, iniciándose un nuevo ciclo de uso" (Smith, 1996: 127).

Aparte de que no hay una manera clara de medir esa "renta potencial del suelo", en la práctica las oscilaciones de los precios de la vivienda debido a la especulación -en unos años en los que el Cabanyal se degradaba a ritmo acelerado, a principios del siglo XXI, los precios de la vivienda se disparaban-, y la incertidumbre en el tiempo de retorno de la ganancia debida a intervenciones políticas o a las circunstancias del escenario económico, hacen que la hipótesis del diferencial de renta resulte más útil como principio orientativo que como ley matemática para explicar esta reestructuración de clase de los paisajes urbanos. Sigue siendo verdad que hay gente - o corporaciones o entidades financiero-políticas- a los que les interesa la degradación de un barrio, que ganan con ella...El principio gentrificador dice: "Cuanto peor, mejor". Es verdad también lo que se deriva de la hipótesis, que la gentrificación es un proceso, y que como tal puede detenerse o revertirse, pero nunca identificarse con -sólo- una parte de él, ni con el principio -la degradación-, ni con el final -la sustitución residencial y el aburguesamiento o elitización ya conquistados-.

El PEPRI cayó sobre un barrio que arrastraba una desinversión, degradación y estigmatización desde muchos años atrás; y es importante hacer notar un cierto desliz según el cual el Cabanyal se habría despoblado a partir del PEPRI, como se ha afirmado:

"[...] en términos cuantitativos, la década del 2002-2012, ha supuesto la pérdida de 5.313 vecinos" (Santamarina, 2014: 312).

"[...] la pérdida de población, en concreto el 20,3 \% en la última década, [...]" (Santamarina; Moncusí, 2013).

Tales datos son extrañamente erróneos. Según la información que consta en la Oficina de Estadística del Ayuntamiento valenciano, entre el año 1981 y el 1996 el barrio pierde casi un $20 \%$ de la población, unas 5.000 personas; en cambio, del año 1996 al 2013 pierde...463 vecinos. Ya Atkinson (2000) advirtió de lo difícil que resulta cuantificar los desplazamientos que provocan los procesos gentrificadores, "como medir lo invisible", debido muchas veces a la falta de datos. Los desplazamientos del Cabanyal previos al PEPRI fueron ur- 
banísticamente silenciosos: una buena parte de la generación vieja del baby boom -en casi todas las familias se dio algún caso más o menos próximo, pero sería muy difícil dar una cifra exacta- fue desplazada al cementerio desde finales de los ochenta, mientras que los más jóvenes emprendíamos una huida quizá generalizable a todos los barrios obreros de la época, lo que se podría llamar un baby boom flight ${ }^{26}$.

Los hijos nos fuimos del barrio y los padres -los que vivían fuera de la zona cero de las 1650 viviendas, claro-, se quedaron y mantuvieron tenaces en los años de plomo del PEPRI, cuando la mitad del barrio se caía a pedazos. Viejos, propietarios -el Cabanyal nunca sobrepasó el $4 \%$ de vivienda en alquiler- y con cierto arraigo, haría falta mucha más presión para desplazarlos. Los vecinos de la zona cero, sin embargo, no fueron desplazados à la Marcuse, sino desalojados à la Lees, es decir, "obligados a abandonar su hogar mediante sobornos y acoso" (Lees, 1994) y mobbing inmobiliario (Santamarina, 2014). Se generaron dos ritmos de gentrificación, uno lento y sutil por desinversión, el que ya padecía el barrio desde hacía décadas, y otro rápido por ocoso y chantaje de corporaciones público-privadas en la zona cero ${ }^{27}$.

Sólo el delirio que da el absolutismo político puede explicar la pretensión de expropiar 1650 viviendas en una zona repleta de construcciones declaradas Bien de Interés Cultural por el Ministerio de Cultura, casas en propiedad de sus habitantes, viejos y arraigados, a los que se les ofrecían cantidades por debajo del precio de mercado en una zona que ya parecía Fort Apache y bajo la amenaza de una próxima expropiación a un precio ridículo, y a los que al mismo tiempo se les daba la posibilidad de aceptar otra casa en usufructo más o menos distante del centro en función de lo que pudieran pagar por ella. Sin parar mientes en el daño emocional provocado, aparente y sorprendentemente sin ningún pudor, el entonces Teniente de Alcalde del Ayuntamiento de Valencia -y sumo "Regidor de Grandes Proyectos" del Ayuntamiento-, el ahora presunto delincuente Alfonso Grau, declaraba "lo que no puede ser es regalarle luego la casa al hijo, al nieto o al primo" ${ }^{28}$. Era el negocio inmobiliario del siglo en la ciudad, teniendo en cuenta que después de derribar las casas adquiridas mediante extorsión y venderles una nueva a los desplazados, había que edificar bloques residenciales y de servicios hasta el mar en una de las mejores zonas de la ciudad -y en la que los desalojados ya no podrían soñar comprarse una casa-.

26 Habría que añadir, pues, estas formas de desplazamiento a las ya señaladas por Tom Slater a partir de los trabajos de Peter Marcuse (hijo de Herman Marcuse, lo que se nota agradablemente), a saber: El "desplazamiento directo del último residente" (por el declive físico de los edificios o la subida de los precios del alquiler), el "desplazamiento excluyente" (por no poder adquirir ya una casa en el barrio debido a la subida de precios), el desplazamiento "de cadena directa" (cuando tenemos en cuenta la "cadena" de propietarios que ha tenido una vivienda) y el "desplazamiento por presión" cuando va dejando de existir un mundo de relaciones al que uno está adaptado y no se ve futuro en uno nuevo que se viene encima. El baby boom flight tendría que ver con el primer tipo de desplazamiento y en parte con el último:el deterioro generalizado de un entorno, de unas relaciones sociales, de unos vínculos comunitarios, -provocados en buena medida por la desinversión y desvalorización continuos que el Estado (o las corporaciones locales) practicaban con el barrio, aumentando con ello el diferencial de renta de año en año-, alimentaban la urgencia de salir huyendo. Que haya un interés en el diferencial de renta explicaría la aparente paradoja señalada anteriormente de que, mientras por un lado se invertían muchos millones en conectar físicamente el barrio con la ciudad, urbanizando sus límites o convirtiéndolos en nodos e hipersendas, por otro lado el barrio por dentro se pudría.

27 Asemejándose a lo que Tom Slater llama slum clearance.

28 Cf. El magnífico documental realizado por Salvem el Cabanyal: El Cabanyal, un barri en resistència contra l'estupidesa; para indignarse sólo hace falta ver y escuchar la intervención de una vecina a partir del minuto 16 y la respuesta alucinante de Alfonso Grau treinta segundos después. Hace poco más de un siglo un "amo" como Grau se podría haber encontrado cerca de alguna acequia al Tío Barret con la hoz en la mano después de ser desahuciado. Por suerte para él, el histórico brutalismo de la huerta y de la pesca ya se había atemperado bastante, por mucho que la alcaldesa se negara a dialogar con los vecinos "porque no se sentaba con violentos". https:// www.youtube.com/watch?v=-CyirC52Wi8 
En lugar de sacar la hoz como el Tío Barret cuando le roban la casa en La Barraca, los vecinos se organizaron en la Plataforma Salvem el Cabanyal en abril de 1998, inspirados por otras plataformas de parecido signo como Salvem el Botànic (1994) y Salvem el Pouet (1997); más tarde surgirían Salvem Velluters (1999), Salvem Benicalap (2000), Salvem El Carme (2001) y Salvem l'horta Vera-Alboraia (2006). "Expresión pública de una herida estructural" (Bono; García, 2006), los Salvem encarnan la resistencia popular ante lo que Neil Smith ha llamado la "ciudad revanchista".

La resistencia vecinal -extraordinaria por las actividades que desplegó durante estos años de plomo y el tesón judicial exhibido, recurso tras recurso hasta el Tribunal Supremo-, detuvo la destrucción de toda la zona cero y la sustitución de clase que llevaría aparejada, pero sólo prolongó el tiempo de la gentrificación: unas 674 casas fueron compradas para ser derribadas, aunque muchas no pudieran serlo debido a los litigios -o a su okupación- y la mayoría no lo fuera porque al Estado-mafia de la Corporación Local le interesaba que se produjera lo que ya era una intensa filtración de pobres, que, en la práctica, serviría como "asustaviejas" de los que permanecían en ese lugar convertido en un escenario post-bélico, salpicado de solares y casas derruidas o tapiadas donde medraban cada vez más familias pobres, traficantes y okupas. Quince años después del PEPRI, en el 2013, en el Cabanyal concentraban el mayor número de infraviviendas de Valencia (el $22 \%$ ), uno de los más altos índices de envejecimiento $\left(137^{\prime} 8\right)$ y una extraordinaria tensión vecinal:

"El desplazamiento de esta población flotante hacia las zonas más deterioradas del Cabanyal genera tensiones. Esta población, mayoritariamente de etnia gitana, arrastrada hacia una cultura de la marginalidad, ha perdido las normas, valores y costumbres del pueblo gitano y el problema se plantea más en términos de convivencia diaria y tráfico de drogas que en términos xenófobos: «Hace unos años atrás el payo y el gitano estaban muy unidos, porque es una barriada muy humilde [...]»" (Bodí; López, 2009: 51).

En el 2015 y en ese contexto, más o menos, las fuerzas de izquierda ganan las elecciones, se paraliza por fin el proyecto de prolongación de la avenida de Blasco Ibáñez y el Ayuntamiento presenta a los vecinos aquello por lo que tanto habían estado luchando los últimos 17 años, la rehabilitación integral del barrio a través de un proyecto denominado $\mathrm{Va} C \mathrm{Ca}$ banyal dirigido por el arquitecto Carmel Gradolí como "Estrategia Integrada de Desarrollo Sostenible del Cabanyal". Con la filosofía del Community Driven, se proponen "empoderar a la ciudadanía" celebrando varias asambleas abiertas donde se discute en círculos sobre el futuro del barrio. Se entrevistan con representantes de los gitanos y las buenas intenciones de un urbanismo con rostro humano desbordan.

Es entonces cuando se produce el cisma entre los movimientos sociales que durante casi veinte años habían peleado juntos:

"Por un lado encontraríamos el bloque que, emocionado con la «voluntad de diálogo» del nuevo consistorio quiere la rehabilitación a toda costa independientemente de sus consecuencias y aquéllos que se posicionan en contra de una rehabilitación que suponga la expulsión de parte del vecindario. El primer grupo vendría encabezado por la plataforma Salvem el Cabanyal, la cara más conocida y mediática del conflicto y el segundo por todo el conjunto de colectivos y centros sociales que trabajan en el barrio y que han venido a configurar una alternativa organizativa conocida como "Espai veïnal Cabanyal”, por un proceso de participación autoorganizado” (Castillejo, 2015). 
En efecto, en el acta de constitución de Espai Vëinal del Cabanyal, el 30 de julio de 2015, advierten del problema: "Estamos presenciando [...] que, tras la paralización tan deseada del proyecto de prolongación de la avenida Blasco Ibáñez, el barrio del Cabanyal se ve afectado directamente por la gentrificación. Una gran parte de la población que reside en el barrio podría verse obligada a marchar por su bajo poder adquisitivo o su condición «marginal» ${ }^{29}$. Trazar una línea de clase entre Salvem y Espai vë̈nal no es difícil: los segundos representan a los más pobres, muchos de ellos okupas ilegales, los primeros a propietarios de clase media.

Las advertencias de que se continúa con la gentrificación del barrio por otros medios se concretan: comienzan los desalojos y el Ayuntamiento amenaza con desalojos masivos, se identifica y registra a cualquier persona que pasee por la zona cero, se multiplican las multas por almacenaje de chatarra, y mientras tanto empiezan a proliferar las inmobiliarias y el capital extranjero (franceses, alemanes, chinos) va adquiriendo propiedades en el barrio, cuyos alquileres empiezan a subir. Para Vicent Gallart, miembro fundador de Salvem el Cabanyal, el proceso gentrificador se habría detenido y únicamente existiría un problema de falta de civismo: ruidos, suciedad, tráfico de drogas, inseguridad; coincidiendo con el Ayuntamiento, considera que la solución a estos problemas tiene que ser el reparto de la bolsa de pobreza por la ciudad.

Pero para hablar de esa bolsa de pobreza debemos antes desarrollar aquella gentrificación amplia que incluía "las transformaciones sufridas en los últimos años [...]: globalización, consumo, turismo, mercantilización del ocio...". En efecto, mientras el Cabanyal entraba en un período de degradación mafiosamente promovido por el las Corporaciones Local y Autonómica, Valencia "se situaba en el mapa del mundo" como ciudad global, para lo cual políticos-empresarios sustituirían la administración de lo común por la venta de una marca, asociada a intercambiables megacomplejos de autor (la Ciudad de las Ciencias, el Palacio de Congresos de Foster, la Marina Real, los circuitos de velocidad....), grandes y elitistas eventos deportivos (hípica, Fórmula 1, tenis, vela) o culturales (visita del papa Benedicto XVI, Campus Party, WTV Winters, etc.), disneyficación generalizada, los megashoppings... Basada en la privatización, banalización y especulación de suelo público, la turistización y mercantilización general que hacen del consumo y del turista con VISA su modelo de ciudad y ciudadano.

Este peculiar advenimiento de la sociedad post-industrial podría ser simplemente una historia paralela a la degradación del Cabanyal, una historia pretenciosa y futurista de fondo, si no fuera por el "keynesianismo perverso" que la inspira: con el principio de la socialización de las pérdidas y privatización de las ganancias, una cosa pagaba la otra...La ciudad global es la ciudad dual:

"Los grandes eventos han contribuido a la generación de una gigantesca deuda pública (29.643 millones de euros, el 29,8\% del PIB valenciano). [...] la Valencia global es, como otros proyectos neoliberales, una ciudad más fragmentada con un aumento de la desigualdad socio-espacial y de la precariedad urbana" (Hernández i Martí, 2015: 62).

Independientemente de si se considera o no oportuno este uso amplio del concepto de gentrificación -que se aplicaría tanto al proceso de degradación/renovación de los barrios como a la construcción de megacomplejos en terrenos baldíos-, lo cierto es que la turistización y terciarización del puerto -convertido en lugar de ocio y consumo, -lo que se ha llamado "gentrificación comercial"- y del paseo marítimo -jalonado por un hotel de seis

29 Cf. https://cabanyalz.wordpress.com/2015/07/30/comunicat-espai-veinal-cabanyal-valenciacastella-per-unproces-de-participacio-autoorg 
estrellas ahí donde antes había un tradicional balneario familiar, Las Arenas-, empujan la gentrificación del barrio por el Sur y el Este, mientras que edificios de nueva construcción -lo que se ha llamado new build gentrification - lo han terminado de unir a la ciudad por el Norte y el Oeste, comiéndole los últimos parches de huerta que lo separaban de ella. Se entiende que, como dice Beatriz Santamarina, el barrio se haya quedado en "el punto cero de los intereses especulativos".

Quizá lo que subyace a esa tendencia a ampliar el uso del concepto "gentrificación" a todos los fenómenos de la globalización no sea más que aquello de lo que ya nos advirtió Engels en su momento:

"En realidad la burguesía no conoce más que un método para resolver a su manera la cuestión de la vivienda, es decir, para resolverla de tal suerte que la solución cree siempre de nuevo el problema. Este método se llama Haussmann. [...]. Entiendo por Haussmann la práctica generalizada de abrir brechas en los barrios obreros. [...]. El resultado es en todas partes el mismo, cualquiera que sea el motivo invocado: las callejuelas y los callejones sin salida más escandalosos desaparecen [...]; pero...callejuelas y callejones sin salida reaparecen prontamente en otra parte, y a menudo en lugares muy próximos" (Marx; Engels, 1975: 638-9).

\section{La sangre de los pobres}

Comenzamos el último apartado con un artículo del diario Levante del 30 de mayo del 2016 en el que se hablaba de una okupación masiva de casas en el barrio con planos y manuales. El periodista nos dice que los okupas le han cambiado el nombre a una calle, la han rebautizado como "Carrer Pepica la Pilona" pegando, encima del viejo cartel, otro nuevo. Nos aclara que "Pepica la Pilona" fue el primer "Centro Social Okupado" del Cabanyal, cuando Salvem y los okupas iban de la mano contra la prolongación de la Avenida...Ese octubre de $1998^{30}$ como dice el artículo del País que da la noticia, "sus nuevos vecinos los recibieron con los brazos abiertos". El "Centro Social Pepica la Pilona" ardió en extrañas circunstancias en el 2006, uno de los años de actividad mafiosa de la Corporación Local.

Tiene a bien añadir el periodista que Pepica la Pilona había sido una "carismática vecina del barrio que estaba enajenada y practicaba la prostitución". En la Historia del Cabanyal de Sanchís Pallarés, en el bello collage o mosaico Benvinguts al Cabanyal y en la monografía etnográfica de Beatriz Santamarina se habla profusamente de ella. Nosotros no la conocíamos como puta, aunque era una de las leyendas que se le asociaban, del mismo peso que aquélla que la hacía madre de un hijo médico o abogado secuestrado hacía muchos años. Al parecer, había nacido en 1919 en el barrio y desde siempre había sido la Pilona. Trataba a todo el mundo como si siguiera viviendo en el viejo Cabanyal, llamándoles "tetes" como allí se llamaba a los hermanos o a los primos. Se movía como un trickster ${ }^{3 l}$, un mediador entre las edades del hombre: A todos parecía conocer, a los abuelos, a los padres y a los hijos; a los mayores les interpelaba siempre pidiéndoles dinero, con gracejo de peixcatera blasquista, mezclando el valenciano y el castellano, a los pequeños nos perseguía para besarnos incluso cuando le gritábamos “¡Pilonaaaa!, ¡Pilonaaa!”. Aunque pudiera entrar en la categoría de "viejas locas" -no era como nuestras abuelas, desde luego-, nunca la vimos hacer o decir cosas incoherentes o incomprensibles, por lo que también debía ocupar algún lugar intermedio entre la razón y la locura.

Decían que vivía en una barca, pero lo más seguro es que estuviera de okupa en alguna

30 Cf. Maroto, Voro, "Varios jóvenes okupan una fábrica del Cabanyal contra el Plan de Blasco Ibáñez”, en El País. Comunidad Valenciana. 6 de octubre de 1998

31 Cf. Lévi-Strauss, 1987: 246-249. 
de las viejas casas abandonadas del barrio. Nadie parecía saberlo. Alimentada entre todos, carroñera como el coyote y con el aspecto de Doña Urraca, alisaba los límites de las partidas internas desplazándose continuamente entre ellas cada día, de frontera en frontera, del Canyamelar al Cabanyal atravesando la cequia del Gas, del Cabanyal al Cap de França cruzando Pixavaques, del Cap de França a la Malvarrosa a través de La Cadena, y vuelta a empezar. Las calles eran de los niños en los setenta, pero también de la Pilona.

Pepica la Pilona tenía algo de vieja estancada en la infancia y una pasión infantil por las películas de los cines de sesión continua ${ }^{32}$, en donde coincidía siempre con la chiquillería del barrio, y allí se convertía en una parte más del espectáculo soltando tacos, eructos o pedos en los momentos más sublimes o tensos, cuando los amantes al fin conseguían besarse, el soldado herido plantaba la bandera en lo alto de la colina o el bueno cazaba al malo: irreverente, procaz o carnavalesca, todos esperábamos más la reacción de la Pilona que el gesto muelle y entregado de los amantes, el sufrido del soldado o el de suficiencia justiciera del bueno, y tras ella todos reíamos mientras pateábamos el suelo entarimado armando un barullo monumental. Como la niebla o el rocío, era una mediadora entre el cielo y la tierra, la que daba el paso entre lo sublime y lo ridículo -Mircea Eliade remarcó la importancia de esta última experiencia para los hombres, reveladora de que, como dicen Heidegger y la sabiduría popular, no somos nada-. Es posible que este sentido carnavalesco de la vida sea un poco propio de la identidad de un barrio cuya extraordinaria Semana Santa mezcla la guardia civil a caballo, granaderos de Napoleón, sayones medievales y cristos con un hombro al aire.

Pepica la Pilona fue recogida por la asistencia social cuando las fuerzas dejaron de bastarle para el merodeo y murió en un hospital de la Malvarrosa en 1994, el mismo año en que el autor de este artículo abandonaba el barrio. Cuatro años después, como dijimos, se abre el "Centro Social Okupado Pepica la Pilona" y veintidos años más tarde los okupas le ponen su nombre a una calle. El nombre es ya un símbolo, no sólo de esa libertad que da ser consciente de que debajo de las convenciones sociales está la nada, sino de la idea de que el suelo no debe ser una mercancía -y mucho menos una mercancía para explotar a trabajadores precarios-, símbolo del derecho elemental a una vivienda.

Los políticos saben que hay formas de contener la gentrificación de una zona : sólo hay que controlar los precios - como ha hecho Anne Hidalgo en París o como se ha hecho en Berlín -, pero en el Cabanyal se da una circunstancia óptima: hay casi cuatrocientas casas que son propiedad pública y que se pueden convertir en viviendas de alquiler social u organizar en cooperativas, y 128 solares que, como defendió Rosa Pastor, profesora del Politécnico de Valencia en un foro reciente, "deberían ser edificados para el retorno de vecinos y para dotarle de las carencias que tenía el barrio"33. Es importante darse cuenta de que, de los cinco objetivos temáticos que plantea la estrategia de desarrollo integral Va Cabanyal, el quinto, es decir, "Promover la inclusión social y luchar contra la pobreza y la discriminación", aunque esté más allá de las posibilidades de arquitectos y urbanistas, es prioritario sobre los otros cuatro, a saber, "mejorar el uso de las TIC", "mejorar la competitividad de las PIME", la "eficiencia energética" y la "protección del medio ambiente", objetivos éstos que parecen responder a regímenes urbanos de clases medias, de ésas que cada vez más se irían filtrando en el barrio.

Si los políticos vuelven a actuar como empresarios y no se despegan del urbanismo neoliberal, el Cabanyal terminará de gentrificarse rápidamente. Los pobres serán desalojados

32 De la extraordinaria afición del barrio por el cine se hace eco Beatriz Santamarina, 2010: 72-ss. En los años cuarenta había seis o siete cines en el área, reducidos a tres o cuatro en los setenta. Recordemos que uno de los objetivos de la aviación italiana en la Guerra Civil fueron los cines del barrio, y que una pareja recién casada murió a las puertas del cine Imperial en uno de esos bombardeos.

33 Cf. Marta Gozalbo, “Debate ciudad. Jornada III. El Cabanyal”, en Valenciaplaza 7/07/2016. 
alegando cualquier cosa -que son ricos o maleantes o simplemente ruidosos- y tendrán que desplazarse a otro lugar, como tuvieron que desplazarse al Cabanyal los pobres que buscaban trabajo en la posguerra o los que perdieron su vivienda en la riada del 57. Si, en cambio, los políticos deciden por inclinarse hacia un régimen urbano orientado a mejorar las condiciones de vida de los sectores populares -conocido como opportunity expansion-, el barrio podrá rehabilitarse sin tener que echar a nadie de una casa por el mero hecho de estar viviendo en ella -si la casa es del común-.

Es posible que por mucha vivienda social que se promueva, el barrio continúe con su proceso de gentrificación, como ha ocurrido en el centro de Bolonia o en algunos barrios de Berlín. Siendo un fenómeno propio del capitalismo, como dice Pierobon (Pierobon, Emanuele, 2015), mientras no podamos abolir al último sólo podremos paliar el primero. Los pobres, que cada vez serán más en la sociedad dual, se harían invisibles por fin en el Cabanyal, -"se repartirían", como pide Vicent Gallart-, y lo que no se ve es como si no existiera. Entonces aparecerían las terracitas, las tiendas modernas y alternativas, los gastrobares y restaurantes exóticos, las galerías de arte, los shoppings y las franquicias. Los viejos cabanyaleros no se marcharían: ¡Han aguantado ya tantas cosas! Se irían muriendo poco a poco, como el barrio de éxito, quejándose de los ruidos y las borracheras de los turistas, quienes sustituirían a los pobres en ese papel, y dejando el piso a otra gente que pagará bastante más por él, con más estudios y cuello blanco, cuya vida girará alrededor del consumo y no del trabajo, del gasto y no del ahorro, de las gratificaciones instantáneas y no de tambores lejanos, de los mundos virtuales, más que de los reales ${ }^{34}$.

El final trágico de Flor de Mayo ocurre encima del espigón del puerto, donde cazábamos cangrejos, en medio de un temporal de levante. La Tía Picores, la vieja peixcatera ordinaria y brutal como la Pilona, le da la espalda al mar, hinchada de rabia y desesperanza:

"Y en lo alto, dominándolos a todos, estaba la Tía Picores, erguida y soberbia como la venganza, indiferente a todos los dolores, con las faldas ondeantes como una bandera azotando sus piernas.

Ya no enseñaba el puño al mar, le volvía la espalda con desprecio, pero amenazaba a alguien que estaba tierra adentro, a la torre del Miguelete, que alzaba a lo lejos su robusta mole sobre la masa de tejados de la ciudad.

Allí estaba el enemigo, el verdadero autor de la catástrofe. Y el puño de la bruja del mar, hinchado y enorme, siguió amenazando a la ciudad, mientras su boca vomitaba injurias.

¿Que viniesen allí todas las zorras que regateaban al comprar en la pescadería! ¿Aún les parecía caro el pescado? ${ }^{35}$... ¡A duro debía costar la libra!" (Blasco Ibáñez, 1895: 264).

\footnotetext{
34 Si Pierobon tiene razón, los que leen y van a conferencias sobre gentrificación son los que dan el perfil del gentrificador (profesiones liberales, cuello blanco, etc.). Volveríamos a ser los rostros pálidos recuperando el territorio perdido. Tal vez Marc Morell acierte al considerar a ambos la misma clase en tanto productora de un plusvalor extraído o añadido - per via di levare o per via di porre- al espacio urbano. Es posible, pero no se olvide que unos no disfrutarán ese plusvalor, los que se acaban yendo.

35 En realidad la novela Flor de Mayo es dos cosas: un homenaje al Cabanyal y una apostilla al bello cuadro de Sorolla "Y aún dicen que el pescado es caro", - y no al revés, como informa erróneamente la página web del Museo del Prado: fue Blasco Ibáñez quien tuvo que ver a Sorolla pintando el cuadro en el taller que éste montó en la playa de la Malvarrosa-, en el que dos pescadores, a derecha e izquierda, atienden a un tercero herido sobre el fondo de la bodega del barco, ligeramente inclinado todavía, suponemos, por el temporal. El de la izquierda, con gesto sereno y resignado, le presiona con paños alguna herida del abdomen, -grave, dada la palidez de mármol de Carrara del cuerpo, de cuyo cuello pende un medallón probablemente con la Virgen del Carmen-, mientras el otro le sostiene desde las axilas levemente inclinado, como la Virgen María a su hijo en la Pietà de Miguel Ángel.
} 
Hoy la Tía Picores -o Pilona- movería el puño unos grados hacia el Sur, por encima de la plaza de Santa Catalina, sobre las jacarandas violetas de la calle de San Vicente, y apuntaría al Ayuntamiento, agitándolo hacia adelante y hacia atrás, así, sin dejar de vomitar injurias, y continuaría desplazando el puño más al Sur, hasta señalar los picos futuristas de la Ciudad de las Ciencias, y nosotros volveríamos a esperar entonces la reacción irreverente, procaz, carnavalesca, de Pepica la Pilona en medio de un barullo atronador.

\section{Bibliografía}

Atkinson, Rowland

2000 "Measuring Gentrification and Displacement in Greater London", en Urban Studies, enero.

Bellet, Carmen

2013 ¿De lo glocal a lo globanal? Las ciudades intermedias en los tiempos de la globalización”, en Cucó, J., 2013.

Benlloch i Calvo, Lluís

2013 "Tras la senda del desplazamiento. Valencia (1995-2007)", Editorialconcreta. <http://editorialconcreta.org/Tras-la-senda-del-desplazamiento>

Blasco Ibáñez, Vicente

1894 Arroz y Tartana, Valencia, Prometeo (1920.)

1895 Flor de Mayo, Valencia, Prometeo (1919).

1898 La Barraca, Madrid, Cátedra (2004)

1902 Cañas y barro, Valencia, Prometeo, (1923).

Bodí Ramiro, Julio

2008 "Posguerra en el Cabanyal: la desmemoria programada", en Miradas, encuentros y críticas antropológicas.

Bodí Ramiro, Julio y López Nicolás, Mireia

2009 "Reordenación urbana, ¿Derechos vulnerados?: el caso del menor en el Cabanyal”, en Documentos de Trabajo Social, $N^{o} 48$.

Boira, Josep Vicent

2005 Informe sobre la encuesta: la imagen de la ciudad de Valencia, Valencia, Ajuntament de València.

1987 El Cabanyal-Canyamelar, Valencia, Ayuntamiento de Valencia.

Boira Maiques, José Vicente y De la Calle Cuevas, Julio

1987 "Geografía, espacio social e imágenes de marca. El análisis de «Flor de mayo» de Blasco Ibáñez”, Saitabi.

Boira Maiques, Josep Vicent y Gaja Díaz, Fernando

1994 "Planeamiento y realidad urbana en la ciudad de Valencia (1939-1989)", en Cuadernos de Geografía, $n^{\circ} 55$.

Boira Maiques, Josep Vicent y Serra, Amadeo (Eds.).

1997 El puerto de Valencia y su entorno urbano. El Grau y el Cabanyal-Canyamelar en la historia. Valencia, Ayuntamiento de Valencia.

Bono, Emerit y García, Ernst

2006 "La societat valenciana i el seu medi ambient", en AAVV, Del territori valencià, Valencia,

Borja, Jordi Federació d'Associacions per la Llengua.

2005 La ciudad conquistada, Alianza, Madrid.

Castillejo, Daniel

2015 "El sol sempre ix pel Cabanyal”, La Veu, Opinions. <http://opinions.laveupv.com/opinio/ blog/6091/el-sol-sempre-ix-pel-cabanyal>

Cerveró i Martí, Lluís

2014 El cabanyal, per exemple (1998-2013). Crònica de quinze anys de resistència. València, Edicions $3 i 4$.

Cucó i Giner, Josepa

2007 "Urbanización y revuelta. Aproximación al caso de la ciudad de Valencia". <www.terracritica.org/fitxers/documents/urbanizacion_y_revuelta.pdf $>$

2013 La ciudad pervertida, Anthropos. 
2013 Metamorfosis urbanas. Ciudades españolas en la dinámica global, (ed.), Barcelona, Icaria.

Damiá, Antonio

1969 Viejo Cabañal. Valencia, Prometeo.

Davidson M. y Lees, L.

2010 "New-buid Gentrification: its histories, trajectories and critical geographies", en Population, Spaces and Place, $\mathrm{N}^{\circ} 16$.

Delgado, Manuel

2007 La ciudad mentirosa: Fraude y miseria del modelo Barcelona, Madrid, La Catarata.

Díaz Orueta, Fernando

2011 "Regímenes urbanos y movimiento ciudadano en Valencia", Cuaderno urbano, Espacio, Cultura, Sociedad-. Vol 9.

Díaz Parra, Ibán

2013 "La gentrificación en la cambiante estructura socioespacial de la ciudad", en Biblio 3W, vol. XVIII.

Esteban, Iñaki

2007 El efecto Guggenheim: del espacio basura al ornamento, Barcelona, Anagrama.

Florida, Richard

2003 The Rise of creative class, N. Y., Basic Books.

Gaja i Díaz, Fernando

2013 "Tras el Tsunami inmobiliario. Salir del atolladero", en Paisajes devastados.

García Herrera, L. M. y Díaz Rodríguez, M. C.

2008 "El proceso de elitización: investigaciones y temas de análisis en la geografía española (1999-2008)", en Scripta Nova. XII, Universidad de Barcelona.

Gómez Ferri, Javier

2004 "Del patrimonio a la identidad. La sociedad civil como activadora patrimonial en la ciudad

Hannerz, Ulf de Valencia", en Gazeta de Antropología, num. 20.

$1980 \quad$ Exploración de la ciudad, México, FCE, 1993.

Harvey, David

1973 Urbanismo y desigualdad social, México, Siglo XXI, 1977.

2005 Breve historia del neoliberalismo, Madrid, Akal.

Hernández i Martí, Gil-Manuel

2015 "La hegemonía cultural del glolugar: entre la relegación y la reivindicación local. El caso de

Hoyt, $\mathrm{H}$. Valencia”, en Política y Sociedad, vol. 52.

1939 The structure and Growth of residential neighborhood_in American cities, FHA, Washington D. C.

Jacobs, Jane

$1961 \quad$ Muerte y vida de las grandes ciudades, Madrid, Capitán Swing.

Koolhaas, Rem

2011 La ciudad genérica, Barcelona, GG.

Lees, Loretta

1994 "Gentrification in London and New York: an atlantic Gap?", en Housing Studies, 9, 2.

Lévi-Strauss, Claude

1957 Antropología Estructural,Buenos Aires, Paidós, 1987.

Ley, D.

1983 A Social Geography of the city, Nueva York, Harper.

Lynch, Kevin

1960 La imagen de la ciudad, Cambridge, MIT; Gustavo Gili 1984.

Mansilla, José

2015 "El triunfo de las clases medias", en Revista de Antropología Experimental, 15 (10), Barcelona.

2016 “Cómo acabar de una vez por todas con la gentrificación”, en Periódico Diagonal, 15/01/2015. Marcuse, Peter

1985 "Gentrification, Abandonment, and Displacement: Connections, Causes, and Policy responses in New York City", en Journal of Urban and Contemporary Law, 28. 
Marx, K. \& Engels, F.

1975 Obras escogidas, Madrid, Akal.

Morell, Marc

2013 “'Gentrificación es lucha de clases': Fronteras y conflictividad en el espacio urbano actual”, en El antropólogo perplejo de José Mansilla.

Mumford, Lewis

1961 La ciudad en la historia, Madrid, Pipas de calabaza, 2013.

Pierobon, Emanuele

2015 "Qué hacer con la ciudad ante la gentrificación", Periódico Diagonal,, 19/12/15.

Park, Robert Ezra

1999 La ciudad y otros ensayos de ecología urbana, Barcelona, Serbal.

Rubio Hancock, Jaime

2014 "Satán es mi arquitecto: introducción al brutalismo", Blogs de El País. <http://verne.elpais. com/verne/2014/10/09/articulo/1412826138_000156.html>

Sanchís Pallarés, Antonio

1997 Historia del Cabanyal. Poble Nou de la Mar (1238-1897), Valencia, Nácher.

2009 Historia del Cabanyal. Siglo XX y un incierto futuro, Valencia, Nácher.

Santamarina Campos, Beatriz

2009 "Cabanyal, cada vez más cerca. Del lugar al espacio como mercancía”, en Zainak, 32.

2010 Hijos del mar, hijos de la tierra. Historias de vida del Cabanyal-Canaymelar. Valencia, Germania.

2014 "La ciudad suplantada. Percepciones sobre los nuevos imaginarios (turísticos) de la ciudad de Valencia", en Pasos, vol. 12.

$2014 b$ "El oficio de resistencia. Salvem y Viu al Cabanyal como formas de contención del urbanis mo neoliberal", en Revista de Dialectología y tradiciones populares, vol. LXIX, nº 2 .

Santamarina Campos, Beatriz y Moncusí Ferré, Albert

2013 "De huertas y barracas a galaxias faraónicas. Percepciones sociales sobre la mutación de la ciudad de Valencia", en Papers, 98/2.

Sequera, Jorge

2015 “A 50 años del nacimiento del concepto «Gentrificación». La mirada anglosajona”, Barcelona, Biblio $3 W$.

Simò, Trinidad

2013 El Cabanyal. Valencia, Universidad de Valencia.

Slater, Tom

2009 "Missing Marcuse: On Gentrification and Displacement", en City, vol 13.

Smith, Neil

1996 La nueva frontera urbana. Ciudad revanchista y gentrificación. Madrid, Traficantes de Sueños, 2012.

Smith, N. y Williams, P.

1988 Gentrification of the city, Boston, Unwin Hyman.

Soja, Edward W.

$2000 \quad$ Postmetrópolis, Madrid, Traficantes de Sueños.

Soriano, Víctor

2015 La huerta de Valencia: un paisaje menguante, Amazon.

Sorribes, Josep (ed.).

2010 Valencia, 1957-2007. De la riada a la Copa de América, Valencia, PUV.

Torres, Vicente

2008 "Nuevos y viejos movimientos ciudadanos en el País Valenciano", en Universitat d'estiu Rafael Altamira. [en línia]: <http://www.univerano.ua.es/es/cursosprevios/cursos2004/movimientos/torresconf.pdf>

Vicent, Manuel

1994 Tranvía a la Malvarrosa, Madrid, Santillana. 